\title{
SocArXiv
}

Preprint : December 31, 2018

URL/DOI GOES HERE

\section{The Emergence of Big Gods in the Ancient Mediterranean}

\author{
Vojtěch Kaše \\ University of West Bohemia
}

\begin{abstract}
Macro-historical data from several independent cultural environments reveal that the emergence of morally oriented religious systems, including representations of powerful and morally concerned deities, represents relatively recent development in human evolutionary history. The cultural evolutionary scholarship disagrees regarding what was the main factor responsible for the emergence and spread of these innovations over the past few millennia. Proponents of the Big Gods Hypothesis suggest that this development should be primarily associated with changes in social complexity, since representations of powerful and morally concerned deities represent a factor promoting cooperation among strangers in large-scale societies and thus a cultural selection advantage for groups adopting these innovations. Advocates of the Affluence Hypothesis suggest that the emergence and spread of morally oriented religious systems has to be primarily coupled with economic development, namely with an increase in affluence, which occurred during the so-called "Axial Age" period. According to this proposal, an increase in affluence enabled adoption of "slow" life-history strategies by certain proportion of the population, what led to emergence of new form of religion, emphasizing morality, long-terms goals and practices of self-control. This paper contributes to this debate by focusing on historical setting often referred to in both of these proposals: the ancient Mediterranean. Using quantitative text analysis methods in analyzing a corpus of ancient Greek texts from the period from $800 \mathrm{BC}$ to $400 \mathrm{CE}$, this study offers a more nuanced view of the process under scrutiny than the one which has been proposed in previous ethnographic and comparative studies. Finding statistically significant differences in the context of usage of the Greek term theos (god) in the texts from the pre-axial and axial period, the obtained results can be more easily interpreted in terms of the Affluence Hypothesis than in terms of the competing account.
\end{abstract}

Keywords: Cultural Evolution, Cognitive Science of Religion, Life History Theory, Big Gods, Affluence Hypothesis, Axial Age, Vector Semantics, Quantitative Text Analysis. 


\section{Introduction}

3 Over the recent years, several hypotheses have been proposed concerning cultural evolution of prosocial religions, i.e. morally oriented religious systems, commonly including representations of powerful and morally concerned deities. Proponents of the Big Gods Hypothesis suggest that this development should be primarily associated with changes in social complexity, since representations of powerful and morally concerned deities represent a factor promoting cooperation among strangers in large-scale societies and thus a cultural selection advantage for groups adopting these innovations (Norenzayan 2013; Norenzayan et al. 2016). Some scholars sharing this perspective view the role of moralizing deities as rather secondary and to be predated by more general beliefs about supernatural punishment (Johnson 2016). Proponents of the Affluence Hypothesis argue that the emergence and spread of morally oriented religious systems has to be primarily coupled with economic development, namely with an increase in affluence, which occurred during the so-called "Axial Age" period. According to this proposal, an increase in affluence enabled adoption of "slow" life strategies by certain proportion of the population, what led to emergence of new form of religion, emphasizing morality, long-terms goals and practices of self-control (Baumard and Boyer 2013; Baumard and Chevallier 2015; Baumard et al. 2015). Both proposals have found some empirical support, either by means of comparative experimental evidence (Purzycki et al. 2016, 2017), by statistical analysis of macrohistorical data (Baumard et al. 2015; Mullins et al. 2018), or by phylogenetic analysis of ethnographic data (Watts et al. 2015).

The current study contributes to this debate by focusing on historical setting often referred to in both proposals: the ancient Mediterranean. Using quantitative text analysis methods in analyzing a corpus of ancient Greek texts from the period of $800 \mathrm{BC}$ to $400 \mathrm{CE}$, this study offers a more nuanced view of the process under scrutiny than what has been offered in previous comparative studies. The obtained results can be more easily interpreted in terms of the affluence hypothesis.

The quantitative text analysis methods have been formerly developed in computer science areas of natural language processing and information retrieval (Jurafsky and Martin 2017) and computational and corpus linguistics (Lüdeling and Kytö 2009; O'Keeffe and McCarthy 2010). More recently, these methods have become increasingly popular in novel fields of computational social science (Cioffi-Revilla 2010) and digital humanities (Jockers and Underwood 2016; Rockwell and Sinclair 2016) and coined by the term Distant Reading (Moretti 2013; Jänicke et al. 2015; Underwood 2017): Instead of reading texts in a traditional way by "close reading", with digitally available corpora, we are invited to count, graph, map and visualize these texts.

The quantitative text analysis methods have a broad sphere of applicability: On the one end of the spectrum, for a traditionally trained scholar in the humanities, the methods can be viewed rather as a tool for additional checking of insights gained previously through close reading of the sources (Czachesz 2016). On the other end of the spectrum, for a social scientist, an analysis of a diachronous corpus can reveal patterns reflecting changes in behavior of the population which produced the texts and to offer insights unavailable by other methods. In this way, these methods have been successfully applied for studying changes of norms in cultural evolution of language (Amato et al. 2018), long-term changes in emotional expressions (Morin and Acerbi 2017) or to examine presence of cognitive bias toward mind-body dualism in texts from ancient China (Slingerland et al. 2017). The current study follows this research 
pathway in an attempt to contribute to an ongoing debate on cultural evolution of prosocial religion.

The proponents of the Big Gods Hypothesis define Big Gods as gods who (a) care about cooperative- and harmony-enhancing behavior, (b) reward and punish, and (c) have the power to monitor all behavior all the time (Shariff et al. 2009, p. 124). They might be distinguished from deities primarily concerned with ritual and ecology (Purzycki et al. 2017, p. 5, Purzycki and McNamara 2016). From cultural evolutionary perspective, as "communities increase in complexity and size, the gods' powers and moral concern also become greater" and "by the time we get to state-level societies, Big Gods predominate and religion becomes intensely intertwined with public morality" (Norenzayan 2016, p. 473). Over the last couple of millennia, "these deities spread culturally and came to dominate the modern world religions like Christianity, Islam and Hinduism" (Purzycki et al. 2016, p. 327). When it comes to Christianity, it is viewed as a movement which "introduce[d] a stronger moralizing component than previous local religions, as well as the adoption of supernatural beings overtly concerned with morality, which were largely absent in earlier ideologies" (Mullins et al. 2018, p. 615).

The Affluence Hypothesis does not focus on representations of gods per se. Its proponents begin with an observation that the morally oriented religious innovations appeared in the most prosperous societies of the time, and among the privileged classes in these societies (Boyer 2018, p. 108). They interpret this observation in terms of life history theory (Stearns 1992), as an increase in affluence can be viewed as an environmental cue triggering a shift from faster to slower life history strategy. For certain segment of society, as the affluence increases, the environment appears to be save and predictable, and since it also becomes reasonable to invest into broader social networks by extended prosociality. Thus, this segment of society also promotes morally oriented religious innovations including beliefs in morally concerned and powerful deities (Baumard and Chevallier 2015, p. 4). Historically speaking, "at some point in the middle of the first millennium BCE, old 'ritual' religions emphasizing short-term strategies would have been supplanted by new 'spiritual' religions that emphasized long-term strategies through asceticism and self-control techniques" (Baumard et al. 2015, p. 4).

The affluence account has been recently criticized both in respect to its theoretical background (Purzycki et al. 2018) and regarding the historical evidence (Mullins et al. 2018). Thus, in an attempt to undermine the Affluence Hypothesis with its emphasis upon changes associated with the Axial Age in the ancient Greece, Mullins et al. claim that the evidence reveals that (1) "universalizing, moralizing ideological traditions and their cultural and institutional manifests did not emerge in Greece during the traditional bounds of the Axial Age $(800$ BCE to $200 \mathrm{BCE})$ ", that (2) "[m]any of the key traits were in place before this period", that (3) no evidence suggests that Greek religious ideology "stressed universalizing or moralizing precepts in any significant way", and that (4) "Greek gods were certainly not omniscient and, crucially, did not much care about what Greek people did from a moral standpoint, provided only that they continued to participate in the proper rituals. Nor was there any widespread punishment for moral transgressions" (Mullins et al. 2018, SI, p. 1). The analysis introduced in this article shows that, taking into consideration the quantitative text analysis evidence, this view is indefensible.

The point that the Greek religion was primarily concerned by participation in rituals and not by belief in gods represents a very popular and widespread opinion. This point has been most famously made by William Robertson Smith in his seminal work on the Religion of the Semites (1989). Smith's sharp opposition between belief and practice in an attempt to liberate 
the study of ancient religion from Christianizing assumptions "ha[s] continued to structure the study of Greek religion to this day" (Harrison 2015, p. 95). Without doubt, the emphasis upon belief made by Christians was exceptional. However, it seems that in a recent scholarship on Greek religion "'belief' has made a comeback, albeit a partial one" (Harrison 2015, p. 97). We should not overlook that for a vast majority of Greeks the existence of gods was an obvious fact, and hence no matter of discussion in everyday life (Versnel 2011, p. 553). Further, from a cognitive science of religion standpoint, it is secondary what exactly it means "to believe" in god. We should instead start with general properties of representations of supernatural beings and what cognitive mechanisms these representations activate (eg. Barrett 2008), as simple presence of religious primes is sometimes sufficient to explain changes in human behavior, regardless of propositional attitudes someone has toward them (cf. Laurin et al. 2012). It is indisputable that the Greeks were representing their gods using roughly the same cognitive machinery as early Christians or participants in the modern experiments. This makes also legitimate the approach adopted in this article.

\section{Materials \& Methods}

The textual corpus The textual data for this project have been retrieved from an annotated corpus of ancient Greek texts made available under Creative Commons AttributionNonCommercial 4.0 International License via GitHub (Celano 2017). The corpus is composed by 910 TEI-XML files and contains altogether 25,522,507 of tagged words. After downloading, all subsequent work with the data has been done using Python 3, Anaconda distribution, in the Jupyter Lab environment, using a number of additional Python packages. All data, scripts and Supplementary Information for this article are available from here: https://osf.io/8j5vm/?view_only=669dc66059744dd8b20593539e9381f1.

The XML files have been parsed using Python ElementTree XML API into a single CSV file and further processed as Pandas dataframe (see the script "1_data-parsing.ipynb"). Having each word coupled with the part-of-speech tags, the dataset has been reduced to contain only words tagged as substantives or adjectives. This way we obtained a dataset of $6,408,492$ words, what is approximetely one fourth of the original text (see "2_data-filteringand-cleaning.ipynb"). We were further working only with the lowercase lemmata of these words and ignored all interpunction.

The texts from individual documents have been grouped on the basis of authorship attribution. In the case of the New Testament and some other texts, where the authorship attribution is dubious or missing, the grouping has been made rather on the basis of a thought school or an authorship community. Thus, for instance, the Gospel of John and Johaninne epistles form one group, assuming that "the Johannine literature is the product of a school, shaped by the vocabulary, idiom, point of view, and worldview of a single seminal teacher" (Painter 2009, p. 345) and has been produced in approximately the same time. This way there has been obtained a list of 113 authors or authorship communities associated with a corpus of 639 documents containing 4,261,135 words (resp. substantives and adjectives only).

However, there still remained some groups of documents not appropriate for our analysis (e.g. volumes of the "Catenae (Novum Testamentum)" containing extractions from texts covering several centuries) or documents with unclear authorship. These groups of documents could not be linked with needed metadata, like the approximate date of origin (in centuries) or 
cultural provenience, and therefore have been omitted from further analysis. For the rest, we manually coded the peak century of activity of each author (e.g. the value "-3.5" means the peak of activity during the fourth century BC) and cultural provenience (either Christian or pagan). We then focused only on authors or authorship communities groups where this could be easily decided with reference to the current scholarly consensus as represented by English Wikipedia (see "3_data-sorting-and-overview.ipynb").

Thus, we finally obtained a dataset of 3,325,960 substantives and adjectives from 512 documents forming 79 groups of authors or authorship communities. Each of these groups has been dated on the century basis (from 8 century BC to 4 century $\mathrm{CE}$ ) and has been classified as either of Christian or pagan provenience (see Fig. 1).

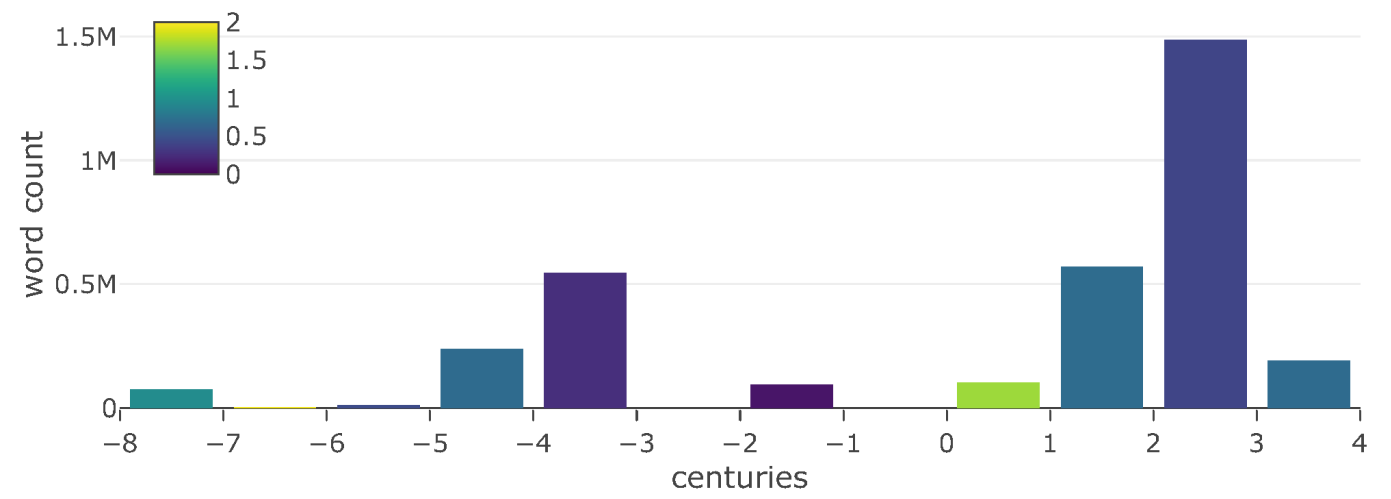

Figure 1: Word counts and relative frequency of the key term by centuries.

Concordance rows To approach differences in understanding of god across the corpus, we further focused on the context of usage of the key term $\vartheta \varepsilon o ́ \varsigma$ (god). For this key term, we extracted concordance data by means of ConcordanceIndex function from Python 3 NLTK package. A generation and analysis of concordances is a common and standardized method both in information retrieval (Jurafsky and Martin 2017) and computational linguistics literature (Sinclair 1991, 2003; Tribble 2010), where a concordance is defined as a "a collection of the occurrences of a word form, each in its own textual environment" (Sinclair 1991, p. 32). The textual environment has a form of a window surrounding the key term and having certain width. For our purposes, we extracted concordance rows of the width of 7 , what means consisting from 3 words before and 3 words after the term as appearing in our pre-processed textual corpus. We replicated the same producedure with the key term ל̧ús (Zeus) (for this and what follows see "4_concordancerows.ipynb").

Indicator terms We further extracted 200 most frequent terms in all concordance rows data of the key term $\vartheta \varepsilon o ́ s$ (god) approached as one corpus. Among them, we manually coded these which can be considered as indicators of the domain of power and morality. To avoid a bias in respect to Christian context, we intentionally omitted terms specific for Christian theol-

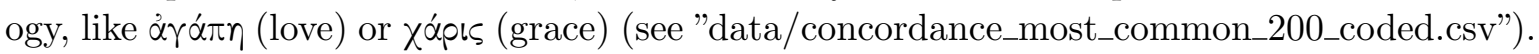
We ended up with 6 morality indicator terms: $\alpha \gamma \alpha \vartheta o ́ s$ (good), $\alpha \lambda \dot{\eta} \vartheta \varepsilon\llcorner\alpha$ (truth), $\alpha \lambda \eta \eta \hat{\eta} \dot{s}$ (uncon-

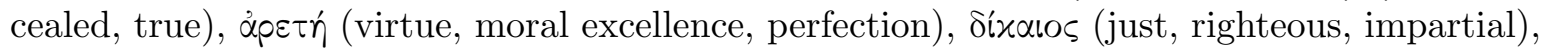




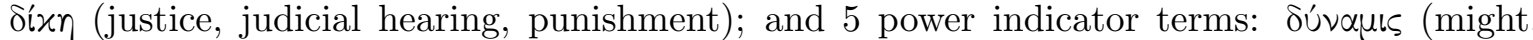

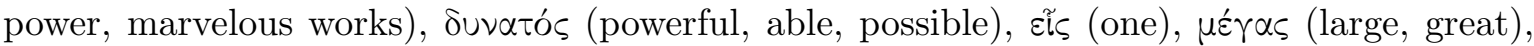
uóvos (only, solitary, desolate). In some cases, we have merged these two categories into one metric. For a diachronical view of the distribution of the indicator terms, see Fig. 2).

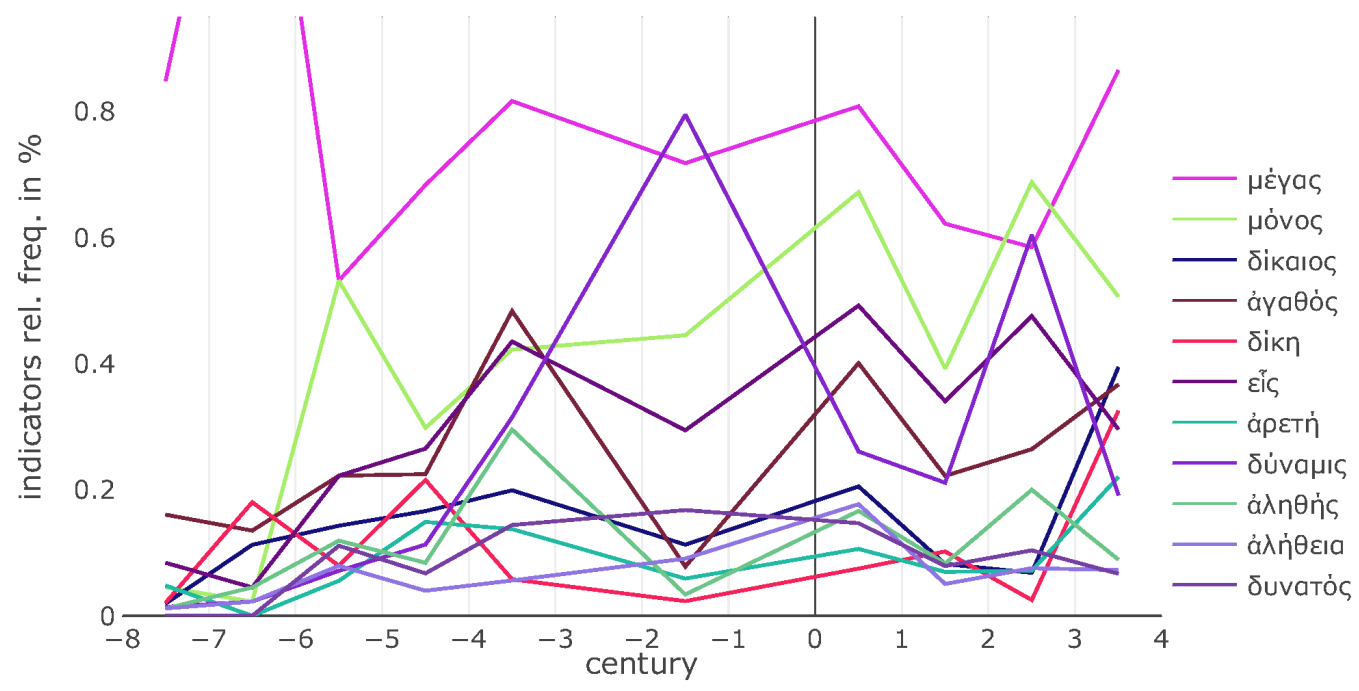

Figure 2: Relative frequency of the indicator terms by centuries.

Mutual Information and Concordance Rows Means To measure the strength of cooccurrence between the key terms and the indicator terms in the concordance data, we firstly adopted the Mutual Information measurement, which compares the probability of observing $x$ (i.e. the key term) and $y$ (i.e. the indicator term) together with the probabilities of observing $x$ and $y$ independently (chance) in the following way:

$$
M I(x, y)=\log _{2} \frac{P(x, y)}{P(x) P(y)}
$$

In linguistics applications, the probabilities are replaced by terms' relative frequencies (Church and Hanks 1990). In our case, the $P(x, y)$ corresponds to the relative frequency of the indicator term $y$ in the concordance rows data of the key term $x$, the $P(x)$ to the relative frequency of the key term in the corpus and the $P(y)$ to the relative frequency of the indicator terms in the corpus. The fraction weights the concordance relative frequencies by corpus relative frequencies, while the logarithm mitigates potentially overrated values for rare terms. This way we obtained the MI score for each indicator term to be compared with scores of other terms and especially across subcorpora.

However, since this method revealed some limitations discussed below, we turned to more elaborated statistical significance testing. In that respect, for each concordance row, we calculated the total number of indicator terms it contains: A concordance row of width of 7 words could contain at maximum 6 indicator terms (plus the key term), but vast majority does not contain any of them. In a weighted variant, each indicator term appearance has been further divided by relative frequency of the term in texts of give author and normalized by logarithm with base 2 , as in the case of MI. 
For the statistical test, we grouped these data either on the basis of dating, cultural provenience or a combination of both. To test whether there is a significant difference between any two groups of data, we applied the Mann-Whitney U test statistic. We checked whether we can reject the null hypothesis that the distributions of both groups are identical, so that there is a $50 \%$ probability that an observation from a value randomly selected from one population exceeds an observation randomly selected from the other population (Nachar et al. 2008).

\section{Results}

Word count distribution overview The analyses below are based on corpus containing 3,325,960 lemmatized substantives and adjectives from 512 documents forming 79 groups of authors or authorship communities. The groups of authors or authorship communities have been further classified on the basis of the peak century of activity of the author or authorship community (from the 8th century BC to the 4th century $\mathrm{CE}$ ) and cultural provenience (Christian or pagan). The data are unevenly distributed over the centuries. On the one hand, the corpus does not include any textual data for the 3rd and the 1st century BC and only a few thousands lemmatized substantives and adjectives for the 7th century BC $(\mathrm{N}=4,441$, the work of Hesiod). On the other hand, the dataset includes 546,663 lemmatized substantives and adjectives for the 4rd century BC and even 1,486,303 lemmatized substantives and adjectives for the 3rd century $\mathrm{CE}$ (for an overview of the data on the century basis, see Fig. $1)$. The most prolific author in the corpus is Galen $(\mathrm{N}=755,012)$. When we divide the data into three sub-corpora each covering an equally long period of 4 centuries, we see an increase from 333,464 words for the period from the 8th to the 5th century BC, through 641,496 for the period from the 4 th century BC to the 1st century BC, to 2,351,000 words for the period from the 1st to the 4th century CE. Thus, the texts from the common era represent most than two thirds of our data. Concerning the provenience, 244,323 lemmatized substantives and adjectives are from Christian sources and 3,081,637 from pagan sources.

Distribution of the key terms The corpus contains 17,299 instances of the Greek term $\vartheta \varepsilon o ́ s$ (god). 7,993 of them are in texts of Christian provenience and 9,306 in texts of pagan provenience. The significantly higher relative frequency of the term among Christian authors $($ mean $=3.22937 \%)$ than among pagan authors (mean $=0.47036 \%)$ is probably caused by the fact that there is a lot of pagan texts of literary genre for which is the topic of religion rather marginal. However, as will be demonstrated below, there seems to be no relationship between

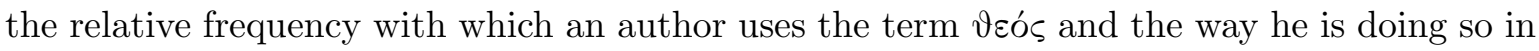
respect to the indicator terms.

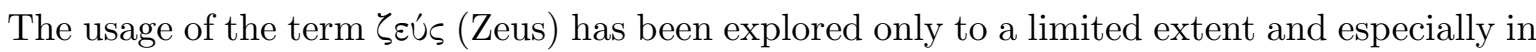
regard to the texts of pagan provenience, among which 5,051 instances have been identified. There has been found a moderate positive correlation between the relative frequency with

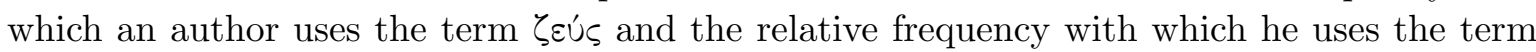
$\vartheta \varepsilon o ́ s(r=0.72626)$. It remained to be settled whether they differ in respect to the indicator terms.

Indicator terms distribution Over the centuries, the relative frequency of the terms coded as indicators of the domain of morality and power is gradually increasing from 0.271592 
$\%$ for morality and $0.991956 \%$ for power in the 8th century BC to $1.468259 \%$ for morality and $1.925722 \%$ for power in the 4th century CE, a time dependent trend captured also by a Pearson's correlation $(\mathrm{r}=0.60746, \mathrm{p}=0.0625)$. However, it is also evident that the increase is neither steady and monothetic. There is a rapid increase between the 5 th and the 4 th century $\mathrm{BC}$ and then, after a decline, again between the 2nd and the 4th century CE (see Fig. 4). We will return to this observation below.

Mutual Information To measure the strength of association between the key term (pri-

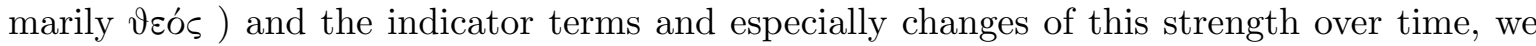
firstly applied the Mutual Information (MI) measurement. Here and in many cases below, we firstly compared scores of individual indicator terms between the data from three periods: early (from the 8th to the 5th century BC), middle (from the 4th to the 1st century BC) and later (from the 1st to the 4th century). However, for this comparison to produce reliable results, we had to modify the standardized MI measurement for the following reason: While applying the MI measurement upon the 200 most frequent terms in the concordance data except the indicator terms (representing our control terms), we observed that the average MI scores substantially differ across the three datasets, giving much higher values for the middle period. We realized that this is primarily caused by the fact that the standard MI measurement implements relative frequency of the key term $(P x)$ - being much lower for the data from the middle period - and that lower values of it produce higher MI score. Thus, to counterbalance this effect, we applied a modified version of the MI measurement with constant $P x$ for all three corpora.

In the case of the control terms, we still obtained slightly changing values over time, with minor increasing trend (early: mean $=7.84438$; middle: mean $=8.39272$; later: mean $=8.50347$ ). However, this is not fatal, since it might be explained by the fact that most concordance data (and hence the control terms based on them) come actually from the later period. What is important, that while applying this modified MI measurement upon the indicator terms. In the case of morality indicators, we observe a different pattern, with highest mean value for the middle period, (early: mean $=7.269$; middle: mean $=8.43421$; later: mean=8.35485). In the case of the power indicators, we again observe a generally increasing trend (early: mean= 7.36273; middle: mean=7.61157; later: mean=7.81516; for individual indicator terms, see Figure 3). Interesting results have been obtained with the key term క̌ús too, where the middle period scores highest in the case of both domains לeús (morality: 7.38037, 8.3042 and 6.68647; power: 6.43907, 6.95669 and 6.81192).

Individual concordance rows and the indicator terms To test for statistical significance of the above observed pattern, we further focused on the number of indicator terms calculated individually for each concordance row, ranging from 0 (most cases) to the hypothetical maximum of 6 (no match in the actual dataset). We subsequently grouped these data either on the basis of dating, cultural provenience or a combination of both and tested statistical independence of potentially interesting pairs of groups of data by applying the Mann-Whitney U test. For each pair of groups we measured whether there is a significant difference in the average number of indicator terms in the concordance rows.

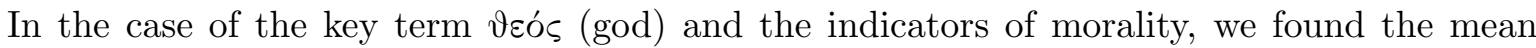
values for the middle period as significantly higher than in the data from the early and later period. In association with morality, we found a significantly increasing trend from the early 

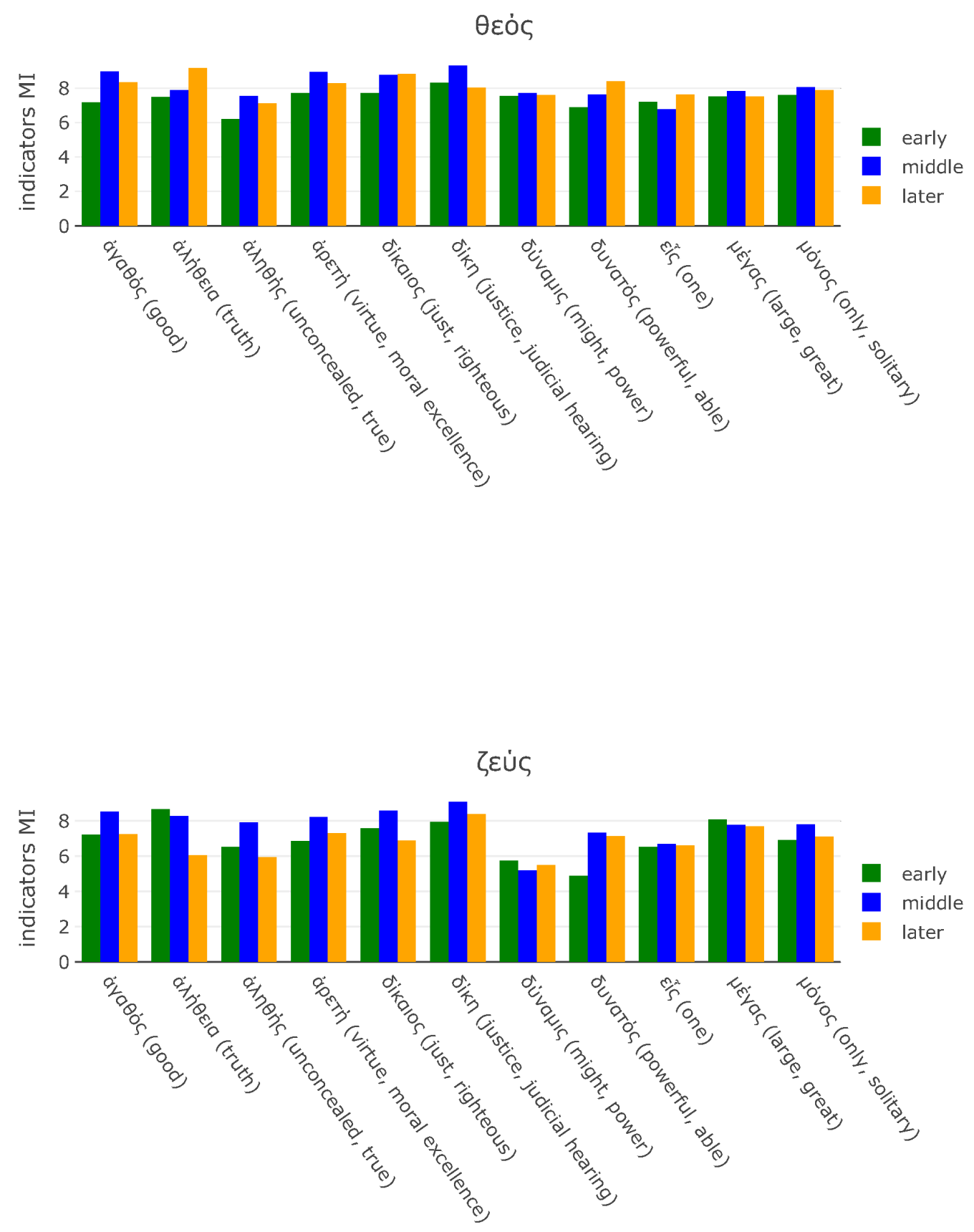

Figure 3: The MI scores with constant $P x$ for co-occurrence association strength of the key

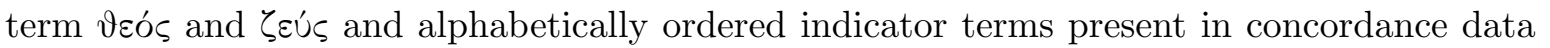
from all three periods. 
to the later period. However, when we combine the two indicator domains, the values for the middle period are significantly higher.

When we compare Christian data with pagan data, we see the Christian god being significantly more associated with power, but not with morality. When we combine the two domains, the Christian god has significantly higher values than the pagan god. Nevertheless, this overall effect disappears when we compare the Christian God with the god of the middle period only.

When grouping the data on the individual century basis (see Figure 4, there is a very strong effect differentiating the data from the 5 th century $\mathrm{BC}$ and the 4 th century BC, present in both domains. This finding appears to be one of the most interesting one and deserves a more detailed exploration (below).

Basically the same pattern is there in the case of the concordance rows data for the key term

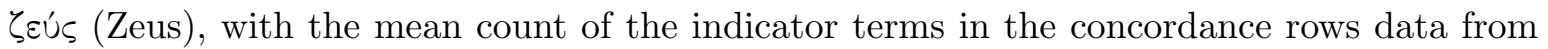
the middle period being significantly higher than in the data from the early period and in the data from the later period. There is also a significant increase between the data from the 5 th century BC and the data from the 4th century BC.

Key terms and the overall distribution of the indicator terms The above introduced results have to be taken with caution, since they do not take into account the overall distribution of the indicator terms in the corpus. As has been documented above (section "Indicator terms distribution"), this distribution also reveals an increasing trend over time. This trend is in agreement with the Affluence Hypothesis, as an increased interest in morality is independent of religious discourse as such. However, it still deserves to be examined what is the association between the overall distribution of the indicator terms in the texts and their distribution in the concordances.

When we look at individual authors (and authorship communities), we see a strong correlation between relative frequency of the indicator terms in all texts from an author and the mean presence of the indicators in the concordance data from the same author $(r=0.72784, p<0.001)$. Since this correlation can be at least partially driven by the presence of the indicators in the concordance data, we further analyzed this association when focusing on the relative frequency of the indicator terms outside of the concordance data. In that case we found a little bit weaker association $(\mathrm{r}=0.66206, \mathrm{p}<0.001)$.

This association requires further examination. One the one hand, the correlation can suggest that the presence of the indicator terms in the concordance data is substantially driven by their overall distribution in the texts. However, we also cannot exclude the possibility that the causation operates in the opposite direction and that the overall distribution of the indicator terms behind the concordance data is at least partly driven by changes in the religious domain, too, while we are not able to capture this by our method. However, a realization of this possibility led us to introduce the findings separately.

This said, it remains to be settled what effect is there when we analyze the instances of the indicator terms in the concordance data while controlling for their overall distribution. For the purpose of analyzing this, instead of simply summarizing instances of the indicator terms in the concordance row as we did above, each one occurrence of an indicator term has been counted as weighted by relative frequency distribution of the term in the works of the author or authorship community from which the concordance row comes. To mitigate disproportion caused by rare terms, the ratio has been further modified by logarithm of base 2 (as in the case of standardized MI measurement). 


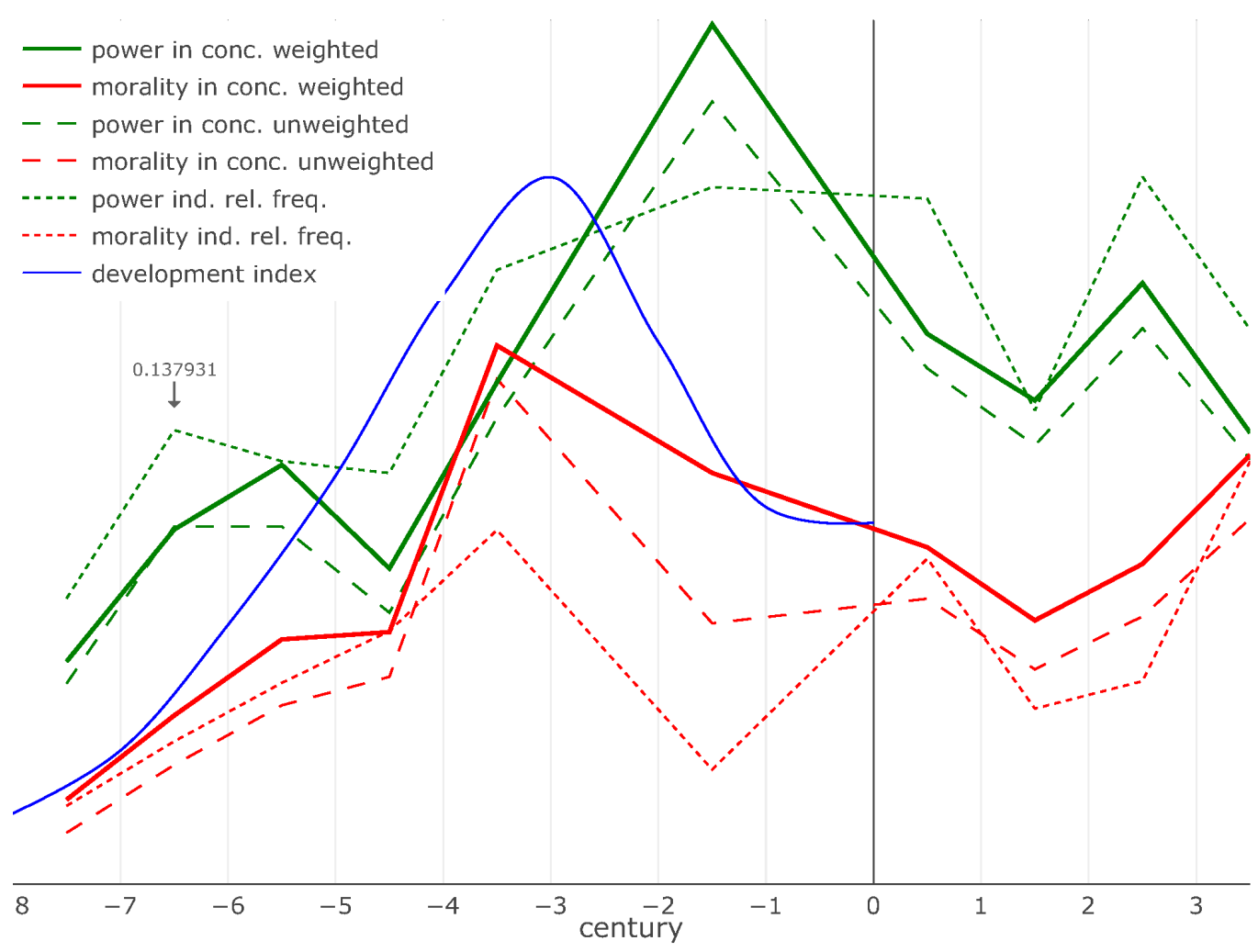

Figure 4: The mean number of indicator terms (morality or power) in the concordance rows weighted by relative frequency of the terms in the author of the concordance ("power in conc. weighted" and "morality in conc. weighted"), The mean number of indicator terms (morality or power) in the concordance rows unweighted ("power in conc. unweighted" and "morality in conc. unweighted"), relative frequency of the indicator terms in the texts ("power ind. rel. freq" and "morality ind. rel. freq"), and the Development Index for "core Greece" area from Ober (2015, Fig. 1.1). 


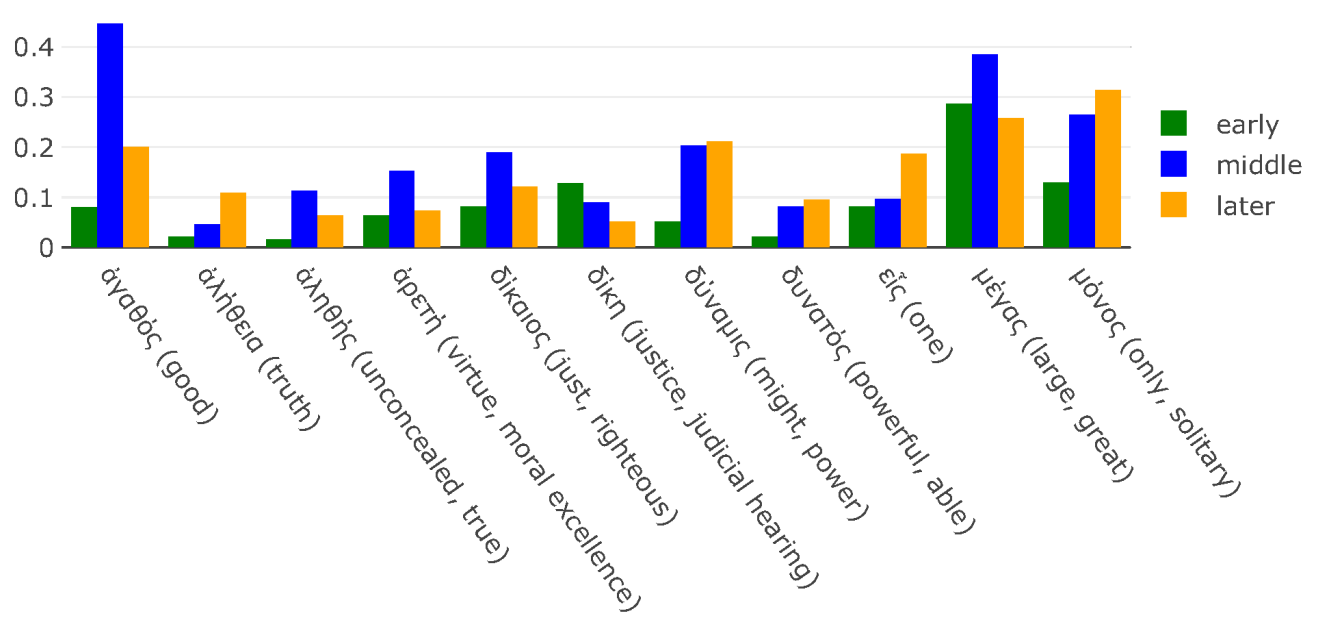

Figure 5: Indicator terms' mean counts in individual concordance rows weighted by relative frequencies of these terms in the texts from author from which the concordance row comes, normalized by logarithm to base 2 .

This results deserve to be introduced in more detail. First looking at the morality indicator terms, we observe a significant increase between the early $(\mathrm{N}=2554$, mean $=0.39415)$ and the middle period $(\mathrm{N}=1536$, mean $=1.04242 ; \mathrm{p}<0.001)$ and then a decrease to the later period $(\mathrm{N}=13209$, mean $=0.62201 ; \mathrm{p}<0.001)$. In the case of power, we see an increase from mean $=0.57509$ to mean $=1.03584$ in the middle period, and then further an increase to mean $=$ 1.06913, which is however not significant ( $\mathrm{p}=0.32109$; for individual terms, see Fig. 5).

Comparing Christian vs. pagan data, our data record the Christian god as being more associated with morality than the pagan god (mean $=0.65633$ vs. mean $=0.59938$ ), but very weakly $(\mathrm{p}>0.077670)$. On the other hand, the mean values of the indicators of power are much higher for the Christian god (mean=1.187 vs. mean $=0.82681 ; \mathrm{p}<0.001)$. However, when we compare the Christian data with the data from the middle period only, the effect in the domain of power is substantially mitigated and the effect of morality is even reversed.

What remains robust under these conditions is the significant difference between the data from the 5 th and the 4th century BC, both in the domain of morality (mean=0.49575 vs. mean $=1.05974 ; \mathrm{p}<0.001)$ and power $(\mathrm{mean}=0.62096$ vs. mean=0.98724). Looking at the data on by-century-basis, we see the highest mean value in the data from the 2 nd century $\mathrm{BC}$ (see Fig. 4). However, since this value is driven by the work of only one author (Polybius), it has to be interpreted with reservation. Viewed in context, the values from Polybius are lower than values from such diverse authors as Theon Smyrnaeus, Irenaeus or Iamblichus.

\section{Discussion}

The results suggest that the most important changes in the understanding of god took place between the early and the middle period, in particular between the 5th and the 4th century BC. This finding remains robust even when we control for the overall distribution of the indicator terms in the texts. Further, what is striking, the god of the middle period appears 
to be even slightly more often associated with terms indicating the domain of power and morality than the god in the Christian texts.

Our findings are in sharp contrast with recently published macro-level analysis of Mullins et al. (2018). Authors of this analysis propose that the Greek religious ideology did not change substantially in the period from $800 \mathrm{BC}$ to $200 \mathrm{BC}$, that the Greek gods, caring primarily about humans participating in proper rituals, were not much associated with power or morality, and that a stronger moralizing component associated with religious ideologies has been actually introduced by Christianity. This is in agreement with the Big Gods Hypothesis.

It seems that according to these scholars the cultural evolution of prosocial religions consisted from two main steps: (1) the appearance of representations of powerful deities in the earliest large-scale societies, like the near-East city states, flourishing a long time before the proposed Axial Age period, and (2) the spread of moralistic ideologies through the world religions like Christianity one or even more thousand years later. As suggested above, these transitions should be interpreted in light of changes in societal complexity, as more complex societies deserve more morally oriented religious systems.

The Axial Age account, supported by proponents of the Affluence Hypothesis, does not fit with this scenario, since the Axial Age period cannot be associated with any substantial changes in societal complexity. Instead of that, as proxies collected by Baumard et al. (2015) suggest, the Axial Age reveals features of extraordinary economic prosperity. In agreement with that, the classical period in ancient Greek history (ca. the 5th and the 4th century $\mathrm{BC}$ ) has been described as a period of exceptional efflorescence, i.e. a period of "increased economic growth accompanied by a sharp uptick in cultural achievement" (Ober 2015, ch. 1).

Drawing on extensive archaeological and historical evidence, Ober (2015) introduced a Development Index for the core Greece region from the late Bronze age to the dawn of the twentieth century. It clearly illustrates the extent of economic prosperity in this region during the period of ancient Greek efflorescence in contrast to both what preceded and followed, as the level of economic prosperity in given region has not returned back to comparable values until the modern age.

In respect to our findings, the Development Index introduced by Ober has its applicability in respect to the data from the early and the middle period, since the data from the later period cannot be directly associated with situation in the core Greece region and should be instead contextualized in respect to the economic situation of the Roman Empire. The Development Index values from $800 \mathrm{BC}$ to $0 \mathrm{CE}$ reveal strikingly similar pattern as the data concerning relative frequency of the indicator terms and their mean count in the concordance rows (see Figure 4. However, since these data are very rough in nature and consist only from a few data points, we do not prove this relationship in a statistically rigid way. Regardless of this limitation, it is evident that our results are much more in agreement with predictions of the Affluence Hypothesis, while undermining some claims proposed by advocates of the Big Gods hypothesis.

To conclude, we sum up some limitations of the current study and suggest promising pathways for future research. First, as mentioned above, the Affluence Hypothesis does not focus on representations of gods per se, but rather on changes in life orientation strategies: a turn toward long-terms goals and practices of self-control (Baumard and Chevallier 2015). Thus, a future research could use quantitative texts analysis methods to analyze changes in usage of concepts associated with these themes rather than with religion as such. Second, as both 
hypotheses explored here have an aspiration to have transhistorical and transcultural validity, the analysis should be replicated on textual corpora from different cultural contexts, too, like ancient China and India. Due to recent digitalization efforts, it seems that this should be possible (cf. Elwert et al. 2015; Slingerland et al. 2017). Third, the texts in our corpus represent only a subselection of extant ancient Greek texts. It is estimated that the amount of ancient Greek and Latin texts already available will almost certainly exceed 1 billion words (Open Latin and Greek Project website). As other digitalized texts will become available in machine readable and linguistically tagged format, we will be happy to use them to replicate our current study. Fourth, the texts in our corpus, typically being product of educated elites, are far from being representative for the population as a whole. To overcome this limitation for given historical context, one possible direction for future research would be to focus on representations of gods in the epigraphic evidence (Taylor 2015). However, on the other hand, this problem is also partly mitigated by the fact that the Affluence Hypothesis assumes that the innovations were introduced by the elites and therefore also intentionally focuses on them (Baumard and Chevallier 2015).

\section{References}

Amato, R., Lacasa, L., Díaz-Guilera, A., and Baronchelli, A. (2018). The dynamics of norm change in the cultural evolution of language. Proceedings of the National Academy of Sciences, 115(33):8260-8265.

Barrett, J. L. (2008). Why Santa Claus is Not a God. Journal of Cognition and Culture, 8(1):149-161.

Baumard, N. and Boyer, P. (2013). Explaining Moral Religions. Trends in Cognitive Sciences, $17(6): 272-280$.

Baumard, N. and Chevallier, C. (2015). The nature and dynamics of world religions: a life-history approach. Proceedings of the Royal Society B: Biological Sciences, 282(1818):20151593.

Baumard, N., Hyafil, A., Morris, I., and Boyer, P. (2015). Increased Affluence Explains the Emergence of Ascetic Wisdoms and Moralizing Religions. Current Biology, 25(1):10-15.

Boyer, P. (2018). Minds Make Societies: How Cognition Explains the World Humans Create. Yale University Press, New Haven - London.

Celano, G. G. A. (2017). Lemmatized Ancient Greek XML (v1.2.5), retrieved from: https://github.com/gcelano/LemmatizedAncientGreekXML.

Church, K. W. and Hanks, P. (1990). Word Association Norms, Mutual Information, and Lexicography. Computational Linguistics, 16(1):22-29.

Cioffi-Revilla, C. (2010). Computational social science. WILEY Interdisciplinary Reviews: Computational Statistics, 2(3):259-271.

Czachesz, I. (2016). Network Analysis of Biblical Texts. Journal of Cognitive Historiography, $3(1-2): 43-67$. 
Elwert, F., Sellmer, S., Wortmann, S., Pachurka, M., Knauth, J., and Alfter, D. (2015). Toiling with the Pāli Canon. In Sporleder, F., Marco, M., and Passarotti, C., editors, Proceedings of the Workshop on Corpus-Based Research in the Humanities (CRH), pages 39-48, Warsaw.

Harrison, T. (2015). Belief vs. Practice. In Eidinow, E. and Kindt, J., editors, The Oxford Handbook of Ancient Greek Religion, pages 91-112. Oxford University Press, Oxford.

Jänicke, S., Franzini, G., Cheema, M. F., and Scheuermann, G. (2015). On Close and Distant Reading in Digital Humanities: A Survey and Future Challenges. Eurographics Conference on Visualization (EuroVis) (2015), pages 1-21.

Jockers, M. L. and Underwood, T. (2016). Text [U+2010] Mining the Humanities. In Schreibman, S., Siemens, R., and Unsworth, J., editors, A New Companion to Digital Humanities, chapter 20, pages 291-306. Wiley-Blackwell, Malden.

Johnson, D. (2016). God is Watching You: How the Fear of God Makes Us Human. Oxford University Press, New York.

Jurafsky, D. and Martin, J. H. (2017). Vector Semantics. In Jurafsky, D. and Martin, J. H., editors, Speech and Language Processing: An Introduction to Natural Language Processing, Computational Linguistics, and Speech Recognition (Third Edition Draft), chapter 15, pages $270-285$.

Laurin, K., Kay, A. C., and Fitzsimons, G. M. (2012). Divergent effects of activating thoughts of God on self-regulation. Journal of Personality and Social Psychology, 102(1):4-21.

Lüdeling, A. and Kytö, M., editors (2009). Corpus Linguistics: An International Handbook, volume 2. De Gruyter, Berlin - New York.

Moretti, F. (2013). Distant Reading. Verso, London - New York.

Morin, O. and Acerbi, A. (2017). Birth of the cool: a two-centuries decline in emotional expression in Anglophone fiction. Cognition and Emotion, 31(8):1663-1675.

Mullins, D. A., Hoyer, D., Collins, C., Currie, T., Feeney, K., François, P., Savage, P. E., Whitehouse, H., and Turchin, P. (2018). A Systematic Assessment of "Axial Age" Proposals Using Global Comparative Historical Evidence. American Sociological Review, 83(3):596626.

Nachar, N. et al. (2008). The mann-whitney u: A test for assessing whether two independent samples come from the same distribution. Tutorials in quantitative Methods for Psychology, $4(1): 13-20$.

Norenzayan, A. (2013). Big Gods: How Religion Transformed Cooperation and Conflict. Princeton University Press, Princeton.

Norenzayan, A. (2016). Theodiversity. Annual Review of Psychology, 67:465-488.

Norenzayan, A., Shariff, A. F., Gervais, W. M., Willard, A. K., McNamara, R. A., Slingerland, E., and Henrich, J. (2016). The cultural evolution of prosocial religions. Behavioral and Brain Sciences, 39(1):e1. 
Ober, J. (2015). The Rise and Fall of Classical Greece. Princeton University Press, Princeton - Oxford.

O'Keeffe, A. and McCarthy, M., editors (2010). The Routledge Handbook of Corpus Linguistics. Routledge, London - New York.

Painter, J. (2009). Johannine Literature: The Gospel and Letters of John. In David E. Aune, editor, The Blackwell Companion to the New Testament, pages 344-372. Blackwell, Malden.

Purzycki, B. G., Apicella, C., Atkinson, Q. D., Cohen, E., McNamara, R. A., Willard, A. K., Xygalatas, D., Norenzayan, A., and Henrich, J. (2016). Moralistic gods, supernatural punishment and the expansion of human sociality. Nature, 530(7590):327-330.

Purzycki, B. G., Henrich, J., Apicella, C., Atkinson, Q. D., Baimel, A., Cohen, E., McNamara, R. A., Willard, A. K., Xygalatas, D., and Norenzayan, A. (2017). The evolution of religion and morality: a synthesis of ethnographic and experimental evidence from eight societies. Religion, Brain $\mathcal{E}$ Behavior, 0(0):1-32.

Purzycki, B. G. and McNamara, R. A. (2016). An Ecological Theory of God's Minds. In Cruz, H. D. and Nichols, R., editors, Advances in Religion, Cognitive Science, and Experimental Philosophy, chapter 8, pages 143-167. Bloomsbury, London.

Purzycki, B. G., Ross, C. T., Apicella, C., Atkinson, Q. D., Cohen, E., McNamara, R. A., Willard, A. K., Xygalatas, D., Norenzayan, A., and Henrich, J. (2018). Material security, life history, and moralistic religions: A cross-cultural examination. PLoS ONE, 13(3).

Rockwell, G. and Sinclair, S. (2016). Hermeneutica: Computer-Assisted Interpretation in the Humanities. The MIT Press, Cambridge, Mass.

Shariff, A. F., Norenzayan, A., and Joseph Henr (2009). The Birth of High Gods: How the Cultural Evolution of Supernatural Policing Influenced the Emergence of Complex, Cooperative Human Societies, Paving the Way for Civilization. In Evolution, Culture and the Human Mind.

Sinclair, J. (1991). Corpus, Concordance, Collocation. Oxford University Press, Oxford.

Sinclair, J. (2003). Reading Concordances: An Introduction. Pearson, London.

Slingerland, E., Nichols, R., Neilbo, K., and Logan, C. (2017). The Distant Reading of Religious Texts: A "Big Data" Approach to Mind-Body Concepts in Early China (preprint). 85(4):985-1016.

Smith, W. R. (1989). Lectures on the Religion of the Semites. A. \& C. Black, Edinburgh.

Stearns, S. C. (1992). The evolution of life histories. Oxford University Press, Oxford - New York.

Taylor, C. (2015). Epigraphic Evidence. In The Oxford Handbook of Ancient Greek Religion. Oxford University Press, Oxford. 
Tribble, C. (2010). What are concordances and how are they used? In O'Keeffe, A. and McCarthy, M., editors, The Routledge Handbook of Corpus Linguistics, chapter 13, pages 167-173. Routledge, London - New York.

Underwood, T. (2017). A Genealogy of Distant Reading. Digital Humanities Quarterly, $11(2): 1-12$.

Versnel, H. (2011). Copying with the Gods: Wayward Readings in Greek Theology. Brill, Leiden - Boston.

Watts, J., Greenhill, S. J., Atkinson, Q. D., Currie, T. E., Bulbulia, J., and Gray, R. D. (2015). Broad supernatural punishment but not moralizing high gods precede the evolution of political complexity in Austronesia. Proceedings of the Royal Society of London B: Biological Sciences, 282(1804):20142556.

\footnotetext{
Affiliation:

Vojtech Kase

University of West Bohemia

Sedlackova 19, 30614 Plzen, Czech Republic

E-mail: vojtech.kase@gmail.com

URL: http://www. vojtechkase.cz
}

https://socopen.org/

https://osf.io/preprints/socarxiv

Submitted: December 31, 2018

Accepted: December 31, 2018 